\title{
An Investigation of the Pedagogical Impact of Using Case-based Learning in a Undergraduate Biochemistry Course
}

\author{
V. Kulak ${ }^{1} \&$ G. Newton ${ }^{1}$ \\ ${ }^{1}$ Department of Human Health \& Nutritional Sciences, University of Guelph, 50 Stone Road East, Guelph, Ontario \\ CANADA, N1G 2W1 \\ Correspondence: Dr. Genevieve Newton, PhD. Department of Human Health \& Nutritional Sciences, University of \\ Guelph, 50 Stone Road East, Guelph, Ontario N1G 2W1, Canada. Tel: 1-519-824-4120-56822, fax: 1-519-763-5902, \\ E-mail: newton@uoguelph.ca
}

Received: July 17, 2015

Accepted: August 21, 2015

Online Published: September 4, 2015

doi:10.5430/ijhe.v4n4p13

URL: http://dx.doi.org/10.5430/ijhe.v4n4p13

\begin{abstract}
The use of case-based learning (CBL) provides students with diverse experiences in the classroom, including problem-solving, knowledge co-construction, communication, and group collaboration. Through these activities, students can explore and develop new knowledge, and acquire relevant skills that have application both in the classroom and beyond. While the majority of studies support the use of CBL as an active learning technique that confers positive pedagogical outcomes, most commonly the investigations compare CBL to a lecture-based method of course delivery. To address this issue, we investigated the pedagogical impact of CBL as compared to a non-CBL "mixture" of other active learning activities in an undergraduate biochemistry course, thereby allowing for a more detailed consideration of the case-specific elements of CBL. It was observed that use of CBL prevented the increase in surface approach to learning that occurred across the semester in the non-CBL group, and improved performance in the course, most notably at the knowledge level of Bloom's taxonomy. As well, there was an improvement in student perception of the appropriateness of the course workload. Overall, these findings support the use of CBL as a preferred active learning technique, and provide valuable insight into the outcomes associated with its use.
\end{abstract}

Keywords: Case-based learning, Active learning, Biochemistry

\section{Introduction}

In 2008, the American Society for Biochemistry and Molecular Biology (ASBMB) reported on the state of teaching in Biochemistry and Molecular Biology and concluded that higher education across levels is driven by content and delivered by lectures, conditions which are associated with a surface approach to learning. The approach to learning describes how students choose to engage with the material being taught, with the deep approach being associated with internalization of content, making learning meaningful, and with personal growth (high-level engagement), and the surface approach being associated with rote memorization and reproducing facts (low-level engagement) with the main goal of passing exams (Marton \& Säljo, 1976). Indeed, studies have shown that the majority of students in biochemistry do take a surface approach to learning and seek to reproduce content (Minasian-Batmanian, Lingard, \& Prosser, 2005; Minasian-Batmanian, Lingard, \& Prosser, 2006; Watters \& Watters, 2007). A large body of evidence points to a failure of lecture-dominated teaching in promoting critical thinking in most students (Anderson, Mitchell \& Osgood, 2005). Therefore, lecture-dominated curricula may distance students from critically interpreting scientific practice and discoveries. To remediate this context, active learning strategies are seen as alternatives or complements to lecture-based or teacher-centered instruction (Fernandez-Santander, 2008).

Several active learning strategies have been proposed across science disciplines to address these pedagogical challenges, for example the use of internships, meaningful research experiences, independent or self-assigned study, concept maps and knowledge translation exercises (Robitaille, 2011; Newton, Bettger, Buchholz, Kulak, \& Racey, 2015). In general terms, active learning derives from constructivist and other contemporary cognitive evidence indicating that experiences and contextualization promote knowledge construction and the retention of information (Ward, 2011; Eberlein et al., 2008; Tiwari et al., 2006). According to Gardner and Belland (2012), active learning encourages students to: (a) practice and self-evaluate discipline-specific content, (b) embrace problem solving as a main goal, (c) develop the ability to build arguments and (d) promote inquiry, all of which are desirable goals in 
science teaching. Active learning that engages students in face-to-face interactions has been shown to decrease failure rates and to prevent learners from passing courses by simply recollecting facts (Freeman et al., 2007). Instructors, who seek active learning as an alternative, are faced with the challenge of choosing a best-of-fit approach for their needs while navigating through a large body of literature encompassing a variety of active learning strategies. Additionally, some of these strategies require significant investment of resources in the form of special classroom layouts, use of technology, or specially trained support staff, in order to be implemented successfully. One strategy that can be implemented in virtually any type of course design is Case-based learning (CBL).

\subsection{Case-based Learning}

Case-based learning (CBL) uses cases as the teaching medium. A case is presented as a narrative where a problem needs to be resolved (Herreid, 1997). Descriptions can be ambiguous but should contain enough detail to facilitate active analysis and interpretation (Kahn \& O'Rourke, 2005; Dunne \& Brooks, 2004). Supporting information is normally provided via research articles, lab results or videos as scaffolding tools to facilitate knowledge construction (Hartfield, 2010; Fardilha, Schrader, da Cruz e Silva, \& da Crus e Silva, 2010; Holton \& Clark, 2006). CBL can be combined or integrated with lectures or other pedagogies thereby assisting in solving a case (Cliff \& Wright, 1996). The goal is to connect concepts by presenting a case that addresses predetermined learning issues or knowledge deficiencies (Hmelo-Silver, 2004). The use of cases in the classroom represents a shift from the traditional pedagogical paradigm that relies on lectures to transfer most of the information. At present, variations of CBL have been adopted worldwide to teach medicine, dentistry, nursing, engineering, general sciences and the humanities (Grady, Gouldsborough, Sheader, \& Speake, 2009). In most variants of CBL, small groups of students are challenged to listen and to make trade-offs with others while confronting their own assumptions and values related to a topic, hence developing effective team work and improving communication skills (Dunne \& Brooks, 2004; Mostert \& Sudzina, 1996), so there is an emphasis on collaboration and discussion activities to solve problems. Also,evidence shows that CBL facilitates accessing Bloom's (1956) higher-order cognitive skills such as application, analysis, synthesis and evaluation more than lecturing alone (Perin, 2011; Fardilha et al., 2010; Dowden, 2007; Rybarczyk, Baines, McVey, Thompson, \& Wilkins, 2007; Davies, 2004). CBL also provides an opportunity to practice and self-evaluate discipline-specific content (Gardner \& Belland, 2012; Passos, Se, Wolff, Nobrega, \& Hermes-Lima, 2006; Cliff \& Wright, 1996). Cumulatively, evidence shows that case studies can be used to teach content, to actively engage students with real-life situations, and to experience decision-making roles typical of professional environments (Hartfield, 2010).

In CBL, students are engaged in the process of inquiry and material is presented on a "need to know" basis: students must become researchers, assemble relevant information and identify key concepts, integrate knowledge, make informed assessments and have group discussions to determine the best solutions to a problem (Herreid, 2000). As reviewed in Kulak and Newton (2014), there are many types of CBL, such as the direct case method, the jigsaw method and the interrupted case method, which vary from each other in the way the cases are presented and in the degree of instructor involvement and student independence. Most CBL types do not require much investment of resources, as there may be no need for a trained group facilitator to guide small group discussions, and cases can be incorporated into lectures within a range of class sizes. Each type of CBL is suitable for use in higher education at all levels provided that case complexity is appropriate to the knowledge base of the students and the subject taught.

For example, while the majority of studies support the use of CBL as an active learning technique that confers positive pedagogical outcomes, most commonly the investigations compare CBL to a lecture-based, method of course delivery (Davies, 2004; Fardilha et al., 2010; Perin, 2011; Rybarczyk et al., 2007). Less frequently, there is comparison between CBL and non-CBL active learning techniques. To address this issue, we investigated the pedagogical impact of CBL as compared to a non-CBL "mixture" of other active learning activities in an undergraduate biochemistry course, thereby allowing for a more detailed consideration of the case-specific elements of CBL.

\section{Methods}

\subsection{Research Questions}

The following research questions were specifically addressed: (1) Does the use of CBL as an active learning technique in biochemistry affect student learning approach? (2) Does the use of CBL as an active learning technique enhance student perception of the course experience? (3) Does the use of CBL improve student performance on the final exam, both generally and across different levels of Bloom's taxonomy? It was hypothesized that compared to the non-CBL group, use of CBL would encourage students to take a deeper approach to learning, enhance impressions of the quality of the course, and improve performance on the final exam. Although the context of the 
present study may be limited to a specific course, CBL has a broad history of use across educational disciplines; our findings are therefore relevant to instructors in higher learning across an array of fields of study.

\subsection{Subjects}

Subjects in this study were students enrolled in a Kinesiology program that leads to a Bachelor of Applied Science degree. Subjects were enrolled in four separate offerings of the same second year biochemistry course (Fall 2012, $\mathrm{n}=64$ students; Winter 2013, n=42 students; Fall 2013, n=63 students; and Winter 2014, n=41 students), which is taught by the same instructor. Each course runs for twelve weeks, with content presented in modules that describe human metabolism. The Fall 2012 and Winter 2013 classes comprised the non-CBL control group, while the Fall 2013 and Winter 2014 classes comprised the CBL intervention group. All students in each course were invited to participate in the study, with respondents giving informed consent and completing the retention test as follows: Fall 2012 (non-CBL) n=45; Winter 2013 (non-CBL) n=41; Fall 2013 (CBL) $n=61$; and Winter 2014 (CBL) $n=42$. Classes were combined into a single non-CBL $(\mathrm{n}=86)$ and $\mathrm{CBL}(\mathrm{n}=103)$ group.

\subsection{Case-Based Learning}

In the present study, the directed type of CBL was used (for a review, see Kulak \& Newton, 2014). This type of CBL is very versatile and allows for lectures or other pedagogies to be combined with the case study. As well, it does not require much investment of resources since trained facilitators are not required for each group of students. The cases are accompanied by a set of questions with close-ended answers and supporting material that can be presented with the aid of figures, tables, and texts. This CBL type allows the instructor to set time limits and to monitor the construction of information to prevent students from diverging from the main topic, thus it is a suitable technique to teach content heavy courses such as biochemistry (Cliff \& Wright, 1996. The cases used in this study were designed following the protocol delineated in Kulak and Newton (2014).

As illustrated in Figure 1, each module in the course involved four tasks, including orientation to the case study, a relevant lecture, peer instruction, and case review. Between the case orientation and the peer instruction, students had approximately four days to find answers to the directed questions. Each group was self-selected and comprised of five to seven students, and each student was assigned one to two questions to answer, with seven questions per case. During the peer teaching time, each student presented their answer to the rest of their group; this was followed by a 45-minute large class case wrap up period that was facilitated by the instructor in which groups shared their answers and received instructor feedback.

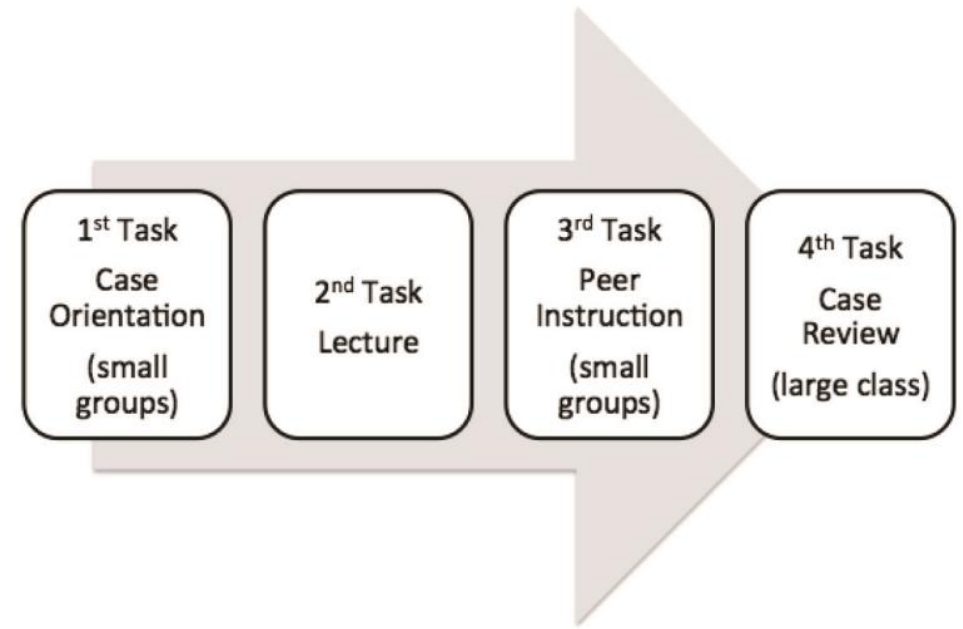

Figure 1. CBL process for each module.

\subsection{Non-CBL Active Learning Approaches}

In the non-CBL control group, students were exposed to the same lectures as the CBL group. Instead of tasks one, three, and four described in figure 1, students participated in a variety of general active learning activities that involved application, analysis, and synthesis. These activities were similarly done in self-selected small groups. Table 1 presents a brief description of the activities in both the non-CBL and CBL groups. The time dedicated to small group active learning activities in the non-CBL group was approximately equal to the CBL group. 
Table 1. Active learning activities and case studies associated with each course module

\begin{tabular}{lll}
\hline Module number and topic & $\begin{array}{l}\text { Non-CBL } \\
\text { Active Learning Activity }\end{array}$ & $\begin{array}{l}\text { CBL } \\
\text { Case Study }\end{array}$ \\
\hline Module 1: Glycogen Metabolism & $\begin{array}{l}\text { Compare and contrast the anabolic } \\
\text { and catabolic pathways of glycogen } \\
\text { metabolism }\end{array}$ & $\begin{array}{l}\text { Baby Chloe, born with a glycogen } \\
\text { storage disease }\end{array}$ \\
Module 2: Glycolysis & $\begin{array}{l}\text { Generate a concept map that } \\
\text { illustrates the relationships between } \\
\text { glucose, fructose and galactose } \\
\text { metabolism }\end{array}$ & $\begin{array}{l}\text { Baby Phillip, born with hereditary } \\
\text { fructose intolerance }\end{array}$ \\
& &
\end{tabular}

Module 3: Citric Acid Cycle

Module 4: Electron Transport Chain

Module 5: Gluconeogenesis

Module 6: Lipid Metabolism

Module 7: Protein Metabolism

Module 8: Metabolic Integration
Predict the outcome of five metabolic disturbances to the citric acid cycle

Trace the pathway of a pair of electrons as they travel from three different substrates all the way to oxygen

Determine the number of substrates and products if starting from three different precursors

Translate the anabolic and catabolic pathways of lipid metabolism into "common" language

Illustrate the process of nitrogen metabolism across three tissues in two metabolic states

Summarize the metabolic activities of three tissues in four metabolic states
Grant, an aid worker in a developing country, with beriberi

Alicia, a bodybuilder taking an usnic acid weight loss supplement

Damien, a glycogen loading marathon runner

Carl, who developed alcoholic fatty liver disease after Frosh week

Timothy, a man with a urea cycle defect on the Atkins diet

Luiza, who went on a 28 day juice fast

As shown in Table 1, each module focused on one metabolic theme. Pseudonyms were used for all the characters in the case studies provided to the CBL groups.

\subsection{Student Approach to Learning}

Student approach to learning was measured using the Revised Two-Factor Study Process Questionnaire (R-SPQ-2F). This questionnaire is designed to measure whether students take a deep or surface approach to learning. It is a revised version of the original Study Process Questionnaire (SPQ) designed by Biggs (1987). The R-SPQ-2F is a statistically validated tool that consists of 20 questions (Biggs, Kember, \& Leung; 2001), and following the factor analysis performed by Justicia, Pichardo, Cano, Berbén and De la Fuente (2008), we considered only the surface and deep scores in our investigation. Biggs et al. (2001) suggest that the R-SPQ-2F is a useful tool to assess teaching innovations and evaluate teaching and learning in the classroom, which was a specific aim of the present study. The R-SPQ-2F has been successfully used in a repeated measures application where it determines changes in the learning 
approaches of the students over time (Groves, 2005; Tiwari et al., 2006; Mok, Dodd, \& Whitehill, 2009), similar to the present study. R-SPQ-2F scores were measured at the beginning of the semester in week one, following an introduction to the course, and again after completion of the final exam.

\subsection{Student Perception of Course Experience}

Student perception of the course experience was measured using the Course Experience Questionnaire (CEQ). The CEQ was developed by Ramsden (1991) and validated by Wilson, Lizzio and Ramsden (1997) to be used as an indicator of teaching effectiveness at the level of the whole course or degree in institutes of higher education. The CEQ measures subjective course experience across five subscales: Good Teaching, General Skills, Appropriate Assessment, Appropriate Workload, Clear Goals. There are several current versions of the CEQ in use around the world; in the present study we used the 23-item version of the CEQ, which was tested for reliability and validity by Waugh (1999) and later refined by Byrne and Flood (2003). The subjects in the study completed the CEQ at the same time as the second R-SPQ-2F, after completion of the final exam.

\subsection{Student Performance}

The final exam was used as the measure of student performance. The final exam was worth $40 \%$ of the final course grade, with approximately $95 \%$ of the same questions in each class. Although several other assessments were used in the courses, many of these were completed in small groups, making it impossible to statistically assess individual performance. The midterm exam was not considered as it tested different content across courses since it was applied at different time points. The distribution of grades across percentile ranges was also considered.

As well, student performance across questions at different levels of Bloom's taxonomy (Bloom, Engelhart, Furst, Hill, \& Krathwohl, 1956) was considered. More recently, Crowe, Dirks and Wenderoth (2008), developed the Blooming Biology Tool (BBT), which was designed to aid faculty and students in developing and identifying science-related questions which are representative of the different Bloom levels: Bloom level 1 is associated with knowledge; Bloom level 2 is associated with comprehension or understanding and Bloom level 3 is associated with application. In this study, the BBT was applied to each question on the final exams, and the accuracy of student responses across different levels was determined. For our analysis, each question on the final exam was independently evaluated by two researchers and was assigned a Bloom level. All exam questions also had a mark value, ranging from one mark for a multiple-choice question to fifteen marks for a short-answer question. These mark values were used to determine the proportion of possible marks from each level available on the exam. A percentage of correct responses at each Bloom level were determined for each student, as in Crowe et al. (2008). For example, if there were 40 marks available from level 1 questions and a student earned 20 of those marks on the exam, they were given $50 \%$ accuracy at level 1 .

\subsection{Data Analysis}

Statistical analyses were done using Microsoft Excel for Mac 2011. F-tests were conducted for each group to confirm unpaired distributions. Unpaired, two-tailed Type 2 and 3 Student T-tests were used to compare all groups across all categories of the R-SPQ-2F, CEQ, final exams and Bloom levels. The chi-square test was used to determine whether there was a significant difference between the frequency distributions of the two groups. All statistical analyses were run with a confidence internal of $95 \%$. Significance was set at $p<0.05$.

\section{Results}

\subsection{Learning Approach}

There was no difference between the groups in the change in deep learning approach across time. Both groups showed a very small reduction in their deep approach to learning from the beginning to the end of the course. However, there was a significant ( $\mathrm{p}=0.025$ ) difference between $\mathrm{CBL}$ and non-CBL groups in the change in surface learning approach across time, with students in the CBL group showing a negligible increase in surface approach in contrast to the approximately two point increase shown by students in the non-CBL group. The change in learning approach across time is illustrated in Figure 2. 


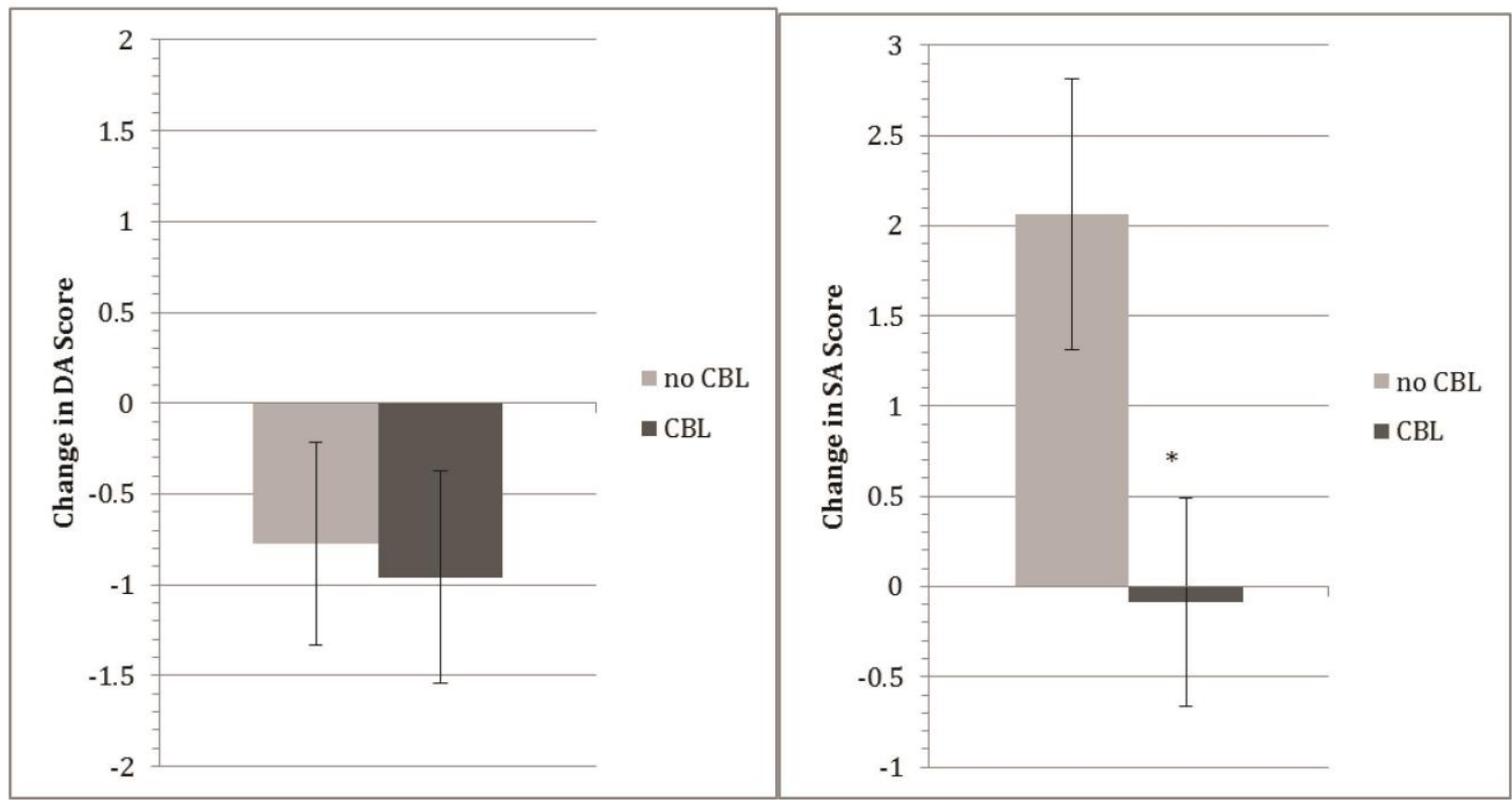

Figure 2. Change in learning approach across time in both CBL and non-CBL groups. There was a significant difference between CBL and non-CBL in the change in SA score. DA = deep approach score, SA = surface approach 3.2 Course Experience Questionnaire (CEQ) score, as measured by the R-SPQ- $2 \mathrm{~F}$.

The CEQ measures subjective course experience across five subscales: Good Teaching, General Skills, Appropriate Assessment, Appropriate Workload, Clear Goals. The CBL group perceived significantly more appropriate assessment in the course $(\mathrm{p}=0.02)$; all other subscales were comparable between the CBL and non-CBL groups, although there was a statistical trend $(\mathrm{p}=0.08)$ for students in the CBL group to perceive good teaching lower. The perception of course experience as measured by the CEQ is illustrated in Figure 3.

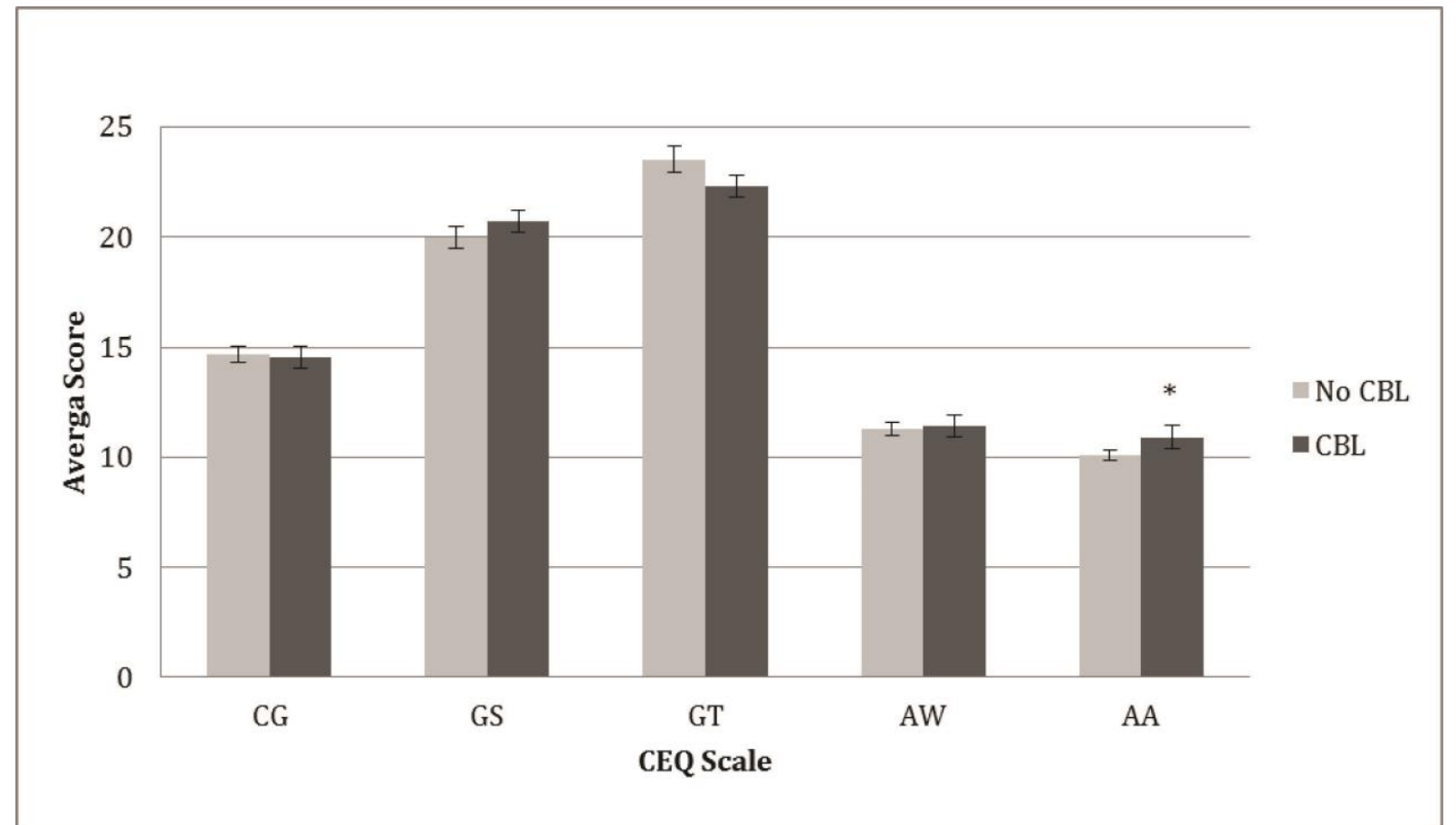

Figure 3. Average score in each subscale of the CEQ. There was a significant difference between CBL and non-CBL in the AA score $. \mathrm{CG}=$ Clear Goals, $\mathrm{GS}=$ General Skills, $\mathrm{GT}=$ Good Teaching, $\mathrm{AW}=$ Appropriate Workload, $\mathrm{AA}=$ Appropriate Assessment, as measured by the CEQ. 


\subsection{Final Exam Performance}

The CBL group performed significantly better on the final exam than the non-CBL group ( $\mathrm{p}=0.03$ ) (Figure 4). There was also a significant difference $(\mathrm{p}<0.001)$ between the two groups in the distribution of grades, with more A's in the CBL group (Figure 5). At the knowledge level (level one) of Bloom's taxonomy, the CBL group performed significantly better than the non-CBL group $(\mathrm{p}<0.001)$ (Figure 6), which suggests that use of CBL may have increased student's general knowledge base in biochemistry. There were no differences between the CBL and non-CBL group at the levels of comprehension (level two) or application (level three).

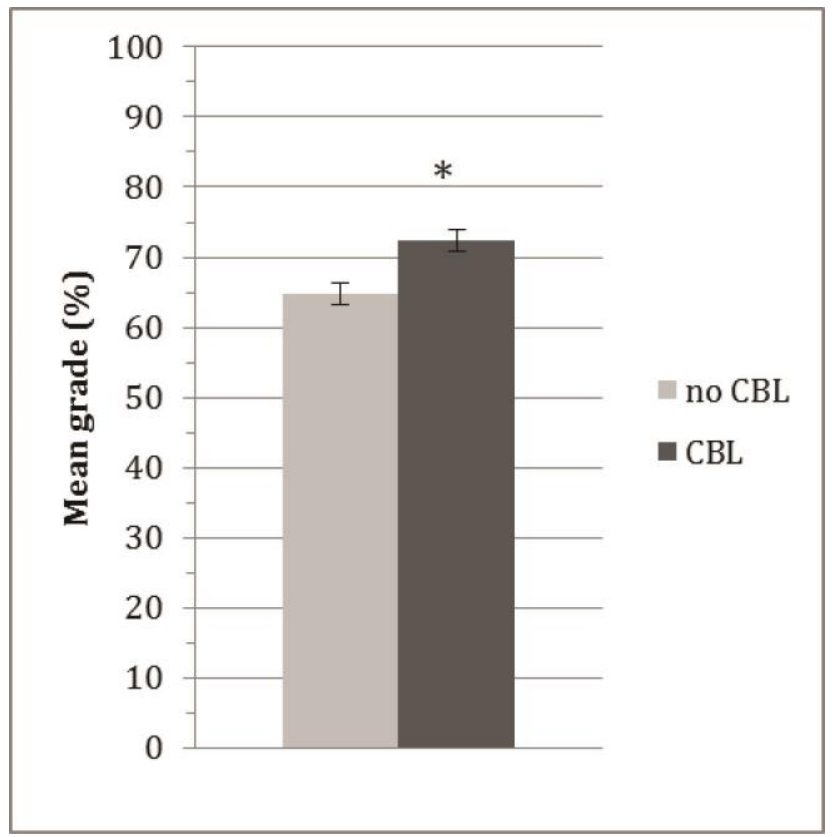

Figure 4. Final exam grades between CBL and non-CBL groups. Students in the CBL group showed a significantly higher grade than students in the non-CBL group.

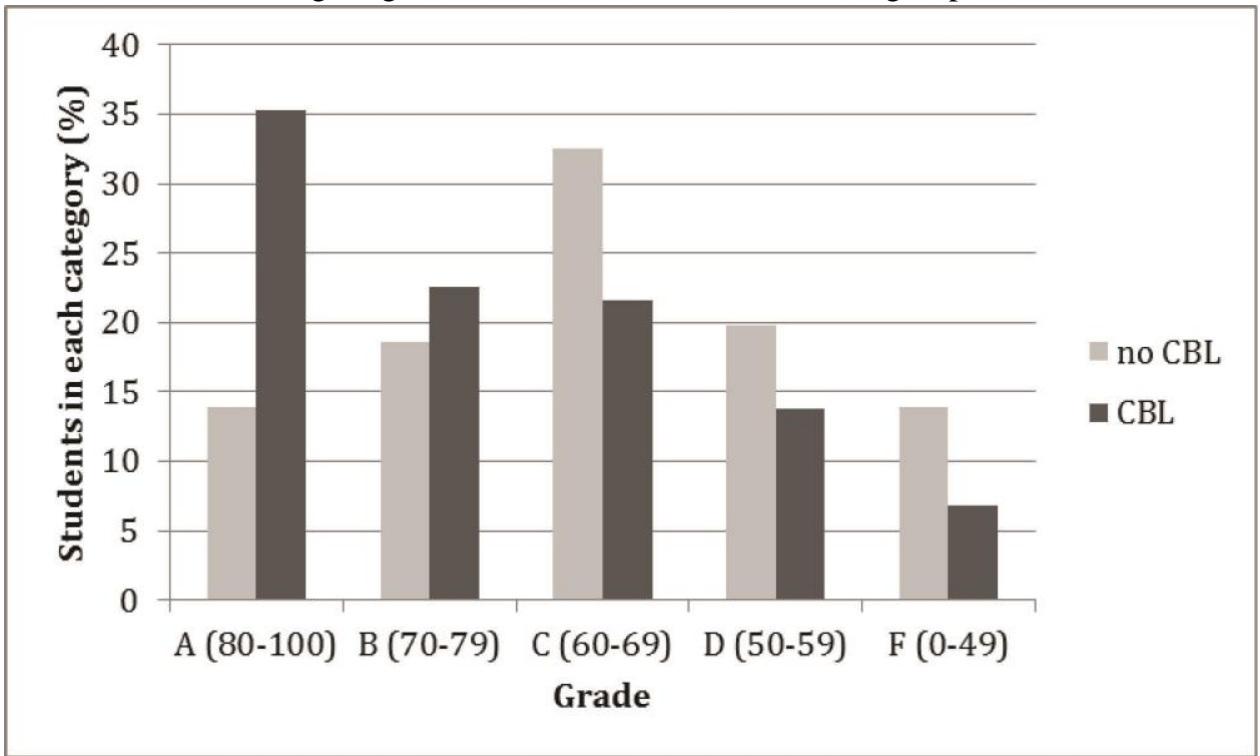

Figure 5. Distribution of grades across letter grades and percentiles in the CBL and non-CBL group. Students in the CBL group showed a significantly greater distribution of A grades than students in the non-CBL group. 


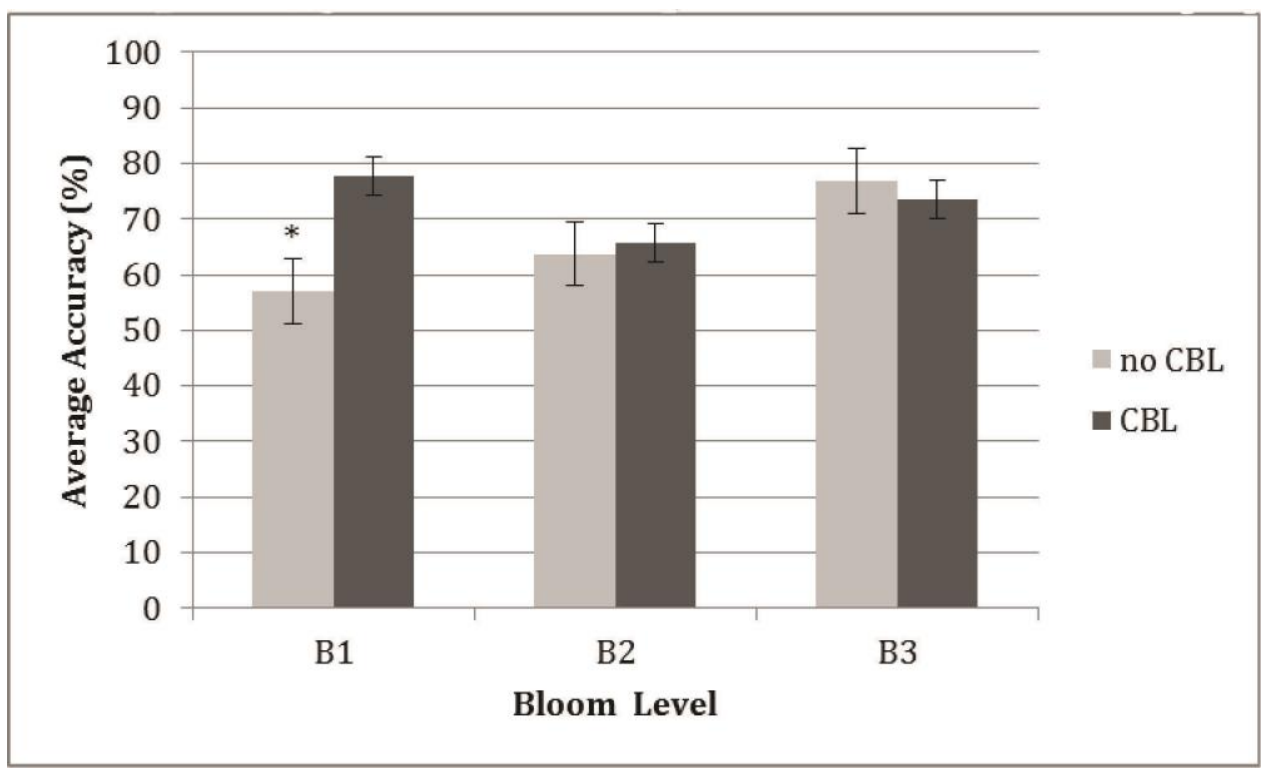

Figure 6. Student performance across evaluated levels of Bloom's taxonomy. Students in the CBL group showed a significantly better performance across questions at the knowledge level, or level one. B1 = Level One (Knowledge), B2 = Level Two (Comprehension/Understanding), B3 = Level Three (Application).

\section{Discussion}

The objective of the present study was to investigate whether the use of CBL as an active learning technique conferred positive pedagogical outcomes in an undergraduate biochemistry course. It was observed that use of CBL prevented the increase in surface approach to learning that occurred across the semester in the non-CBL group, and improved performance in the course, most notably at the knowledge level of Bloom's taxonomy. As well, there was an improvement in student perception of the appropriateness of the course workload. Overall, these findings support the use of CBL as a preferred active learning technique, and provide valuable insight into the outcomes associated with its use.

\subsection{CBL Effect on Learning Approach}

The biochemistry course in the present study is typical in that it delivers a large volume of content, and students must decide how they are going to approach their learning. As reported by Minasian-Batmanian et al. (2005; 2006), students in compulsory biochemistry courses progressively adopted a surface approach towards the end of the course, which was accompanied by a difficulty in seeing the relevance of the information being taught. The authors noted that most students had the prior conception that in order to succeed in the course, they needed to "attend classes, read the textbook and learn the subject by reproducing" information. However, with respect to learning approach and academic performance, Watters and Watters (2007) found a strong statistical correlation between approach to learning and achievement in introductory biochemistry: students who adopted a deep approach generally performed better on exams, as long as the context of learning was based on problem-solving; so, a deep approach to learning is preferred, and a shift towards a surface approach should be viewed negatively. Similar to Minasian-Batmanian et al. (2005; 2006), in the present study, we observed that students in the non-CBL group adopted a progressively more surface approach to learning from the beginning to the end of the course, although this modification was not observed in students in the CBL group, which suggests that the CBL experience may have discouraged the surface approach shift. And, it is likely that a greater change in learning approach would have been observed if the CBL group had been compared to a traditional didactic presentation of course material, instead of the non-CBL group that also participated in active learning activities. This speculation arises from observations reported in the comparative study in biochemistry education done by Bevan, Chan and Tanner (2014), who compared several active learning techniques to a traditional lecture based course. They found that there was a significant increase towards the surface approach in the lecture based biochemistry course by the end of the study period and a reduced tendency towards the deep approach, while the students exposed to active learning saw less change in the tendency toward the deep approach. Therefore, our results are consistent with the findings by Bevan et al. (2014) and build on their work by demonstrating that using case studies as an active learning technique is associated with favourable learning approach changes across time as compared to a mixture of non-CBL active learning techniques. 


\subsection{CBL Effect on Student Performance}

Research conducted by Crowe et al. (2008) and Zheng, Lawhorn, Lumley and Freeman (2008) suggests that the analysis of the accuracy of student responses to questions across different levels of Bloom's taxonomy may be an appropriate way to evaluate student learning across varying levels of cognition. In this study, use of CBL was associated with higher accuracy at the knowledge level. Non-CBL students performed at approximately 57\% accuracy at the knowledge level, and at $64 \%$ and $77 \%$ at the comprehension and application levels respectively, while in the CBL group, students performed at approximately $78 \%$ at the knowledge level, $66 \%$ at the comprehension level and $74 \%$ at the application level. When considering these findings, it is relevant to note the levels of questions in relation to question type. The knowledge questions were almost exclusively multiple-choice, while the comprehension and application questions were short answer. Clearly, students in the non-CBL group struggled to answer the multiple choice knowledge questions while those in the CBL group did not, suggesting that use of CBL may have increased student's general knowledge base in biochemistry. This may be related to the use of directed questions that broadly covered the content of each module, rather than a single active learning activity that may not have had as wide a scope. The observation that students in both groups performed equally at the application level suggests that both $\mathrm{CBL}$ and non-CBL types of active learning support higher levels of cognitive challenge.

\subsection{CBL Effect on Perception of Course Experience}

Although we originally hypothesized that use of CBL would be associated with an improvement in student perception of the course experience, we only observed a small increase in the perception of appropriate assessment with use of CBL. We hypothesize that this may be related to the clear attribution of grades to the CBL work. Although the grade contribution from active learning activities was equivalent in both non-CBL and CBL groups, at $16 \%$ of the final grade (2\% from the activity - case or non-case - in each module) students may have perceived this as higher with CBL as there was more consistency between assessments in each module. In general, however, the two groups showed only very small differences in course perception, although there were considerable differences in perception across different subscales, with scales such as good teaching and general skills being ranked much higher than appropriate workload and assessment. The results of the analyses of course perception suggest that use of CBL as an active learning activity, as compared to non-CBL active learning activities, are not divergently perceived by students.

\subsection{Study Limitations and Strengths}

This study has both limitations and strengths that should be considered. The limitations include a small $\mathrm{n}$, a lack of randomization, and the application of the pedagogy in a single course and discipline. However, we attempted to mitigate these issues by recruiting subjects across four courses, and by including a non-CBL group as a quasi-control, which strengthens the study design considerably. As well, CBL has a long history of use in a variety of different disciplines (Grady et al., 2009), so although research findings in a single field may not be generalizable, the research nonetheless contributes to the general understanding of the impact of CBL pedagogy and could serve as a framework for similar research in other disciplines. Another notable strength of this study is the comparison of CBL to non-CBL active learning, rather than to traditional lecturing, which is relevant given the increasing shift towards incorporating these pedagogies into the classroom. It may also be viewed as a strength to have used the directed method of CBL, which in contrast to some other types of CBL, requires less of an investment of resources and is appropriate for content heavy courses that may need to combine lectures with active learning activities (for a review, see Kulak \& Newton, 2014).

\subsection{Conclusion}

This paper considered the use of case studies in undergraduate biochemistry education, and demonstrated that using cases in this context conferred positive pedagogical outcomes, including preventing a shift towards surface learning and improving academic performance, particularly at the level of foundational knowledge. The use of CBL provides students with diverse experiences in the classroom, including problem-solving, knowledge co-construction, communication, and group collaboration. Through these activities, students can explore and develop new knowledge, and acquire relevant skills that have application both in the classroom and beyond. As we move away from lecture dominated teaching towards using more active and student-centered approaches, there are several notable research gaps to be addressed. In the domain of problem-based learning, many important issues have yet to be investigated thoroughly, such as measuring outcomes beyond single courses and programs, and with extended follow-up. Collaboration between researchers is essential, including collaboration among researchers teaching in the same degree programs, as well as across programs and institutions. It is only through the accumulation of a network of 
evidence that a comprehensive understanding of the short- and long-term impact of problem-based learning on learning and performance will emerge.

\section{References}

American Society for Biochemistry and Molecular Biology. (2008). Biochemistry/Molecular Biology and Liberal Education: A report to the Teagle Foundation. Available at: http://www.teaglefoundation.org/teagle/media/library/documents/learning/2008_asbmb_whitepaper.pdf?ext=.pd f

Anderson, W., Mitchell, S., \& Osgood, M. (2005). Comparison of student performance in cooperative learning and traditional lecture-based biochemistry classes. Biochemistry and Molecular Biology Education, 33, 387-393. http://dx.doi.org/10.1002/bmb.2005.49403306387

Bevan, S.J., Chan, C.W., \& Tanner, J.A. (2014). Diverse assessment and active student engagement sustain deep learning: A comparative study of outcomes in two parallel introductory biochemistry courses. Biochemistry and Molecular Biology Education, 42(6), 474-479. http://dx.doi.org/10.1002/bmb.20824

Biggs, J.B. (1987). Student Approaches to Learning and Studying. Hawthorn, Vic.: Australian Council For Educational Research.

Biggs, J., Kember, D., \& Leung, D. Y. P. (2001). The revised two factor study process questionnaire: R-SPQ- 2F. British Journal of Educational Psychology, 71, 133-149. http://dx.doi.org/10.1348/000709901158433

Bloom, B. S., Engelhart, M. D., Furst, E. J., Hill, W. H., \& Krathwohl, D. R. (1956). Taxonomy of educational goals. Handbook I: Cognitive domain. New York (NY): David McKay Company.

Byrne, M., \& Flood, B. (2003). Assessing the teaching quality of accounting programmes: An evaluation of the Course Experience Questionnaire. Assessment \& Evaluation in Higher Education, 28(2), 135-145. http://dx.doi.org/10.1080/02602930301668

Cliff, W., \& Wright, A. (1996). Directed case study method for teaching human anatomy and physiology. Advances in Physiology Education, 15, S19-S28. Retrieved from http://advan.physiology.org/content/ajpadvan/270/6/S19.full.pdf

Crowe, A., Dirks, C., \& Wenderoth, M.P. (2008). Biology in bloom: Implementing bloom's taxonomy to enhance student learning in biology. CBE - Life Sciences Education, 7, 368-381. http://dx.doi.org/10.1187/cbe.08-05-0024

Davies, M. (2004). The successful use of case studies in nutritional biochemistry. Georgia Journal of Science, 62, 79-86.

Dowden, T. (2007). Relevant, challenging, integrative and exploratory curriculum design: Perspectives from theory and practice for middle level schooling in Australia. Australian Educational Researcher, 34, 51-71. http://dx.doi.org/10.1007/BF03216857

Dunne, D., \& Brooks, K. (2004). STLHE Green guide no. 5: Teaching with cases. Retrieved from http://www.mcmaster.ca/stlhe/publications/gree.guides.htm

Eberlein, T., Kampmeier J., Minderhout, V., Moog, R.S., Platt, T., Varma-Nelson, P., \& White, H.B. (2008). Pedagogies of engagement in Science. Biochemistry and Molecular Biology Education, 36, 262-273. http://dx.doi.org/10.1002/bmb.20204

Fardilha, M., Schrader, M., da Cruz e Silva, O.A.B., \& da Cruz e Silva, E.F. (2010). Understanding fatty acid metabolism through an active learning approach. Biochemistry and Molecular Biology Education, 38, 65-69. http://dx.doi.org/10.1002/bmb.20204

Fernandez-Santander, A. (2008). Cooperative learning combined with short periods of lecturing: A good alternative in teaching biochemistry. Biochemistry and Molecular Biology Education, 36(1), 34-34-38. http://dx.doi.org/10.1002/bmb.20141

Freeman, S., O'Connor, E., Parks, J.W., Cunningham, M., Hurley, D., Haak D., ...Wenderoth, M.P. (2007). Prescribed active learning increases performance in introductory biology. CBE-Life Sciences Education, 6, 132-139. http://dx.doi.org/10.1187/cbe.06-09-0194 
Gardner, J. \& Belland, B.R. (2012). A conceptual framework for organizing active learning experiences in biology instruction. Journal of Science and Educational Technology, 21, 465-475. http://dx.doi.org/10.1007/s10956-011-9338-8

Grady, R., Gouldsborough, I., Sheader, E., \& Speake, T. (2009). Using innovative group-work activities to enhance the problem-based learning experience for dental students. European Journal of Dental Education, 13, 190-198. http://dx.doi.org/10.1111/j.1600-0579.2009.00572.x

Groves, M. (2005). Problem-based learning and learning approach: Is there a relationship? Advances in Health Sciences Education: Theory and Practice, 10(4), 315-326. http://dx.doi.org/10.1007/s10459-005-8556-3

Hartfield, P. J. (2010). Reinforcing constructivist teaching in advanced level biochemistry through the introduction of case-based learning activities. Journal of Learning Design, 3(3), 20-20-31. http://dx.doi.org/10.5204/jld.v3i3.59

Herreid, C. (1997). What is a case? Journal of College Science Teaching, 27, 92-94.

Herreid, C. (2000). Jigsaw, a case study technique where students become experts. Retrieved from http://ublib.buffalo.edu/libraries/projects/cases/teaching/jigsaw.html

Hmelo-Silver, C.E. (2004). Problem based learning: what and how do students learn? Educational Psychology Review, 16, 235-266. http://dx.doi.org/10.1023/B:EDPR.0000034022.16470.f3

Holton, D., \& Clark, D. (2006). Scaffolding and metacognition. International Journal of Math Education in Science \& Technology, 37, 127-143. http://dx.doi.org/10.1080/00207390500285818

Justicia, F., Pichardo, M.C., Cano, F., Berbén , A.B.G., \& De la Fuente, J. (2008). The revised two-factor study process questionnaire (R-SPQ-2F): Exploratory and confirmatory factor analyses at item level. European Journal of Psychology of Education, 23(3), 355-372. http://dx.doi.org/10.1007/BF03173004

Kahn, P., \& O'Rourke, K. (2005). Understanding enquiry based learning. In T. Barrett, I. MacLabhrainn, \& H. Fallon (Eds.), Handbook of enquiry and problem based learning (pp. 1-10). Manchester: CELT Press.

Kulak, V., \& Newton, G. (2014). A guide to using case-based learning in biochemistry education. Biochemistry and Molecular Biology Education, 42(6), 457-473. http://dx.doi.org/10.1002/bmb.20823.

Marton, F., \& Säljo, R. (1976). On qualitative differences in learning - I: outcome and process. British Journal of Educational Psychology, 46 (1976), pp. 4-11. http://dx.doi.org/10.1111/j.2044-8279.1976.tb02980.x

Minasian-Batmanian, L. C., Lingard, J., \& Prosser, M. (2005). Differences in students' perceptions of learning compulsory foundation biochemistry in the health sciences professions. Advances in Health Sciences Education: Theory and Practice, 10(4), 279-290. http://dx.doi.org/10.1007/s10459-005-1404-7

Minasian-Batmanian, L., Lingard, J., \& Prosser, M. (2006). Variation in student reflections on their conceptions of and approaches to learning biochemistry in a first-year health sciences' service subject. International Journal of Science Education, 28(15), 1887-1887-1904. http://dx.doi.org/10.1080/09500690600621274

Mok, C., Dodd, B., \& Whitehill, T. (2009). Speech-language pathology students' approaches to learning in a problem-based learning curriculum. International Journal of Speech-Language Pathology, 11, 472-481. http://dx.doi.org/10.1080/17549500903003052

Mostert, M.P., \& Sudzina, M.R. (1996). Undergraduate case method teaching: pedagogical assumptions vs. the real world. Retrieved from http://eric.ed.gov/ERICWebPortal/search/detailmini. jsp?_nfpb=true\&_\&ERICExtSearch_SearchValue_0=ED395900

\&ERICExtSearch_SearchType_0=no\&accno=ED395900

Newton, G., Bettger, W., Buchholz, A., Kulak, V., \& Racey, M. (2015). Evidence-informed strategies for undergraduate nutrition education: a review. Applied Physiology and Nutrition Metabolism, 40, 652-661. http://dx.doi.org/10.1139/apnm-2014-0368

Passos, R., Se, A., Wolff, V., Nobrega, Y., \& Hermes-Lima, M. (2006). Pizza and pasta help students learn metabolism. Advances in Physiology Education, 30, 89-93. http://dx.doi.org/10.1152/advan.00044.2005

Perin, D. (2011). Facilitating student learning through contextualization: a review of evidence. Community College Review, 39, 268-295. http://dx.doi.org/10.1177/0091552111416227

Ramsden, P. (1991). A performance indicator of teaching quality in higher education: The course experience questionnaire. Studies in Higher Education, 16, 129-150. http://dx.doi.org/10.1080/03075079112331382944 
Robitaille, N. (2011). The revitalization of undergraduate education in Canada. A report on the AUCC workshop in undergraduate education. Halifax, Nova Scotia. Association of Universities and College of Canada. Retrieved from

http://www.aucc.ca/wp-content/uploads/2011/09/the-revitalization-of-undergraduate-education-in-canada-2011. pdf

Rybarczyk, B.J., Baines, A.T., McVey, M., Thompson, J.T. \& Wilkins, H. (2007). A case-based approach increases student learning outcomes and comprehension of cellular respiration concepts. Biochemistry and Molecular Biology Education, 35, 181-186. http://dx.doi.org/10.1002/bmb.40

Tiwari, A., Chan, S., Wong, E., Wong, D., Chui, C., Wong, A., \& Patil, N. (2006). The effect of problem-based learning on students' approaches to learning in the context of clinical nursing education. Nurse Education Today, 26(5), 430-438. http://dx.doi.org/10.1016/j.nedt.2005.12.001

Ward, P. J. (2011). First year medical students' approaches to study and their outcomes in a gross anatomy course. Clinical Anatomy, 24(1), 120-127. http://dx.doi.org/10.1002/ca.21071

Watters, D.J., \& Watters, J.J. (2007). Approaches to learning by students in the biological sciences: implications for teaching. International Journal of Science Education, 29(1), 19-43. http://dx.doi.org/10.1080/09500690600621282

Waugh, R. F. (1999). A revised CEQ for student evaluation of university courses. Paper presented at the Course Experience Questionnaire Symposium, 1998, University of New South Wales. Retrieved from http://www.aare.edu.au/data/publications/1998/wau98137.pdf

Wilson, K., Lizzio, A. \& Ramsden, P. (1997). The development, validation and application of the Course Experience Questionnaire, Studies in Higher Education, 22, 33-53. http://dx.doi.org/10.1080/03075079712331381121

Zheng, A.Y., Lawhorn, J.K., Lumley, T., Freeman, S. (2008). Application of bloom's taxonomy debunks the "MCAT myth". Science, 319 (5862), 414. http://dx.doi.org/10.1126/science.1147852 